\title{
The Monsoon over the Barents Sea and Kara Sea
}

\author{
Alexander Kislov ${ }^{1}$, Tatyana Matveeva ${ }^{2}$ \\ ${ }^{1}$ Department of Meteorology and Climatology, Lomonosov Moscow State University, Moscow, Russia \\ ${ }^{2}$ Laboratory of Climatology, Institute of Geography, Russian Academy of Science, Moscow, Russia \\ Email: avkislov@mail.ru
}

How to cite this paper: Kislov, A. and Matveeva, T. (2020) The Monsoon over the Barents Sea and Kara Sea. Atmospheric and Climate Sciences, 10, 339-356.

https://doi.org/10.4236/acs.2020.103019

Received: April 16, 2020

Accepted: June 1, 2020

Published: June 4, 2020

Copyright $\odot 2020$ by author(s) and Scientific Research Publishing Inc. This work is licensed under the Creative Commons Attribution International License (CC BY 4.0).

http://creativecommons.org/licenses/by/4.0/

\begin{abstract}
In the Arctic (mainly in its European sector) there is statistically detectable seasonal reversal wind pattern. The combination of seasonally warm (cold) land surfaces in arctic areas together with cool (cool) sea surface of Arctic seas not covered by ice is conducive to the formation of a monsoon like system. On the other hand, the predominance of the cyclonic regime during all seasons makes it difficult to answer the question of whether the Arctic region belongs to the monsoon type pattern. In this study, the monsoon features of atmospheric circulation over the Barents and Kara Seas were analysed. To extract specific monsoon signs, atmospheric circulation systems (separately for areas of each sea) were divided into ten weather types. Their appearance and statistics were compared with indicators of regional circulation. A significant part of intra-annual monsoon variability is associated with the configuration of such modes as the North Atlantic Oscillation and the Scandinavia teleconnection patterns. For example, during the winter season, the monsoon currents (from land to sea) occur only with a positive North Atlantic Oscillation index. With the prevalence of other modes of variability, the direction of the winds can be different, and the regular monsoon circulation pattern is changed by chaotic regime. In summer, northern streams (from sea to land) are realized on the western periphery of cyclones, regenerating and stabilizing over the Kara Sea. As for anomalies, the nature of the monsoons is manifested in the statistics of extreme winds even without selecting data on the regimes of variability. So, in winter, maximum speeds fall on the southern streams, and in the summer-on the northern ones. Large precipitation anomalies during all seasons, as one would expect, are encountered most often with the cyclonic type of circulation.
\end{abstract}

\section{Keywords}

Monsoon, The North Atlantic Oscillation, The Scandinavia Teleconnection Pattern, Barents Sea, Kara Seas 


\section{Introduction}

The Arctic region has heated more rapidly than any region on Earth over the past few decades. This is the so-called Arctic amplification [1], occurring above the "global warming" signal, and resulting mainly from dynamic processes in the atmosphere providing a poleward heat advection [2] [3] [4]. These processes are especially active in the Norwegian Sea and adjacent Arctic regions (the Barents and Kara Seas-see Figure 1). The geographical features of this region cause the Barents Sea (BS) to be a transition zone where the climate is primarily influenced by the North Atlantic Ocean, whereas the climate of the Kara Sea (KS) is more affected by processes over the Arctic Ocean and the Northern part of Asia. Notably, relatively little research has been published on the climate of this region.

In the initial analysis of circulation systems, we divided the data in relation to seasons. We considered that in the Arctic region, July and August are the only true summer months, whereas the winter season covers not only December, January, and February, but rather includes the entire interval from November to April. Therefore, the spring season comprises May and June, and the autumn season covers September and October.

In the cold period, the movement of air masses from the south (from the land to the ocean) prevails over the BS and the KS. In summer, on the contrary, northern flows from the sea to land prevail [5]. It is known that in the 16th century, these features were already being considered by residents (Pomors) engaged in marine fishing [6] [7]. These peculiarities can be interpreted as monsoon effects, and their frequency is $40 \%-60 \%$ according to S. P. Khromov [8].

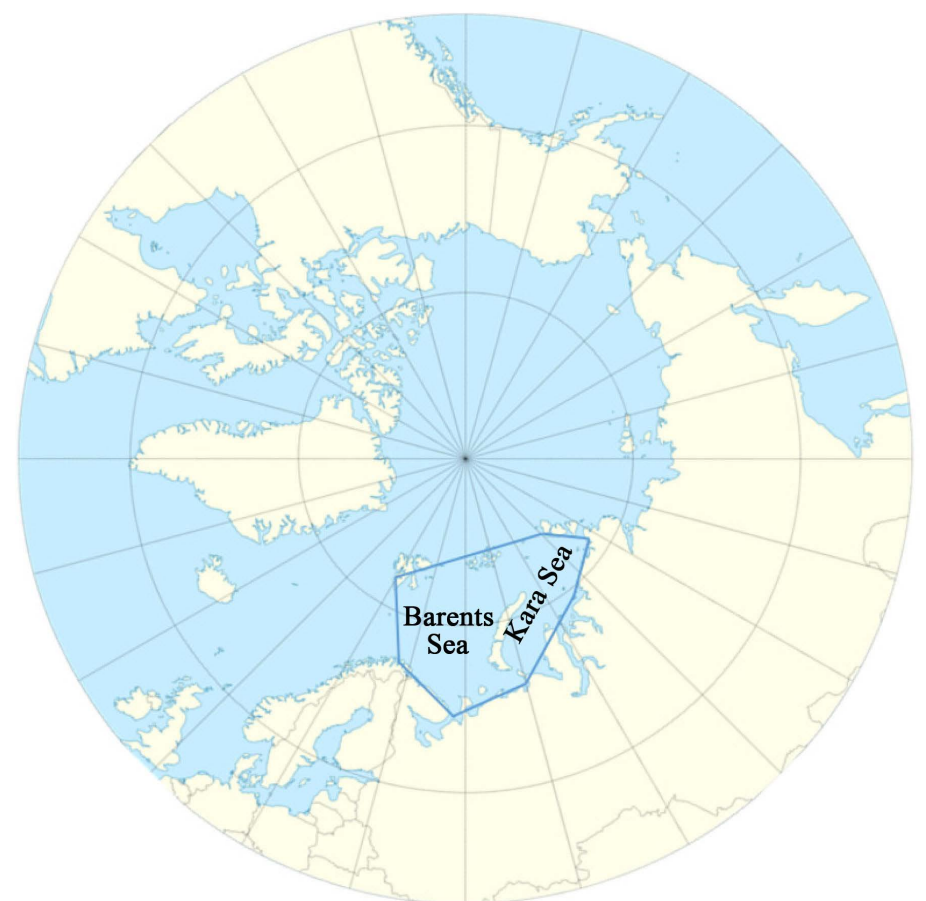

Figure 1. The geographical location of the Barents and Kara Seas. 
K. Ramage [9], specifying the definition of a monsoon climate, excluded the Arctic regions from consideration, because there is no replacement for cyclonic circulation with anticyclonic circulation (and vice versa) in contrasting seasons. He included in the definition that the seasonal wind shifts should not reflect averaging of a shift in the tracks of moving circulations, but rather the replacement of one persistent circulation system by a reverse and equally-persistent circulation system.

Further refinements of the definition of monsoon climate considered the reversal of wind direction and large amounts of seasonal rainfall [10] [11] [12] [13] [14], as well as the features of divergence fields and vertical air movements [15] [16]. Both tropical monsoons and the monsoons of extratropical regions correspond to these definitions. In that regard, there are differences in these regions in the mechanisms of precipitation formation: in extratropical regions, it is connected with polar-front cyclones, whereas in the tropics, precipitation is formed by monsoon depressions that have no connection with atmospheric fronts.

The BS and KS are characterised by a reversal in the low-level wind direction between the summer and winter seasons (as mentioned earlier), and indistinct wet summer and dry winter periods. These seasonal differences occur, despite the fact that cyclonic activity does not fade under the seasonal changes, which is often considered as a stochastic cause of the instability of the regular monsoon circulation pattern. Thus, the predominance of the cyclonic regime makes it difficult to answer the question of whether the region of the BS and KS belongs to the monsoon type pattern. However, regardless of terminological preferences, the analysis of monsoon features is convenient for detecting the variability of circulation systems. In particular, the emphasis on monsoon features allows us to focus on the study of instability in their circulation patterns. The problem can be formulated as follows: why does the monsoon regime manifest itself distinctly in certain years or only in certain seasons, whereas in others it is absent?

From general considerations, we can assume that the regional atmospheric circulation over the Arctic is influenced by the main modes of variability of the Northern Hemisphere [17] [18] [19]. The purpose of this study is to detect these relationships and analyse the factors that determine the seasonal variability of atmospheric circulation, and to study the accompanying variations in precipitation, air temperature, and wind speed in the near-surface layer. As a marine climate is being investigated, reanalysis data are used for analysis.

We begin by identifying the meteorological data used in the analysis, and outline the statistical methods employed in Section 2. Then, in Section 3, we examine the variability in wind, temperature, and precipitation for the BS and KS at seasonal periods within 50 years, in connection with the weather types and main modes of variability. In Section 4, we analyse the relationships between specific types of circulation and anomalies of meteorological values. In Section 5, we discuss the changes in regional atmospheric circulation. Finally, in Section 6, we summarise our principal findings. 


\section{Data and Methods}

We use 6-hour data from the "ERA-interim" dataset on a $1^{\circ} \times 1^{\circ}$ grid from 1979 to 2018 [20], taking into consideration the surface air temperature, precipitation, wind velocity, and relative vorticity. For the analysis of synoptic situations, we used daily synoptic maps prepared by the Federal State Budgetary Institution of the Murmansk Office for Hydrometeorology and Environmental Monitoring (http://www.kolgimet.ru).

The variability in regional circulation systems is often investigated by identifying the individual types of circulation and analysing their time series. There are many such methods, and some are successful [21] [22] [23] [24] [25].

The peculiarities of the regional circulation over the BS and KS are determined using a modified weather typing approach (so-called circulation weather types (CWTs)) after [21] [22]. The CWTs are defined based on regionally-averaged airflow directions (separately for each sea). This approach has been extensively used in applications for climate conditions in Europe. Nevertheless, this approach should be especially successful in the Arctic, because within the Arctic realm, the heat advection (implicitly determined by the CWTs) plays an important role, owing to the large temperature gradients.

For each territory and each day, the flow is classified into eight directional CWTs, namely, north-north-east (NNE), north-east-east (NEE), east-east-south (EES), south-south-east (SSE), south-south-west (SSW), south-west-west (SWW), west-west-north (WWN), north-north-west (NNW), and two rotational CWTs, namely, cyclonic (C) and anticyclonic (A). The $\mathrm{C}$ and $\mathrm{A}$ are specified on the basis of the circulation of the velocity field (and consistent with the definitions used in fluid dynamics). They are practically calculated based on Stokes' theorem as a flux of vorticity, using a summation of the relative vorticity within a contour covering the study area. The motion is considered to be vortex motion if the regionally-averaged vorticity (while considering the square of each grid space) is greater than $20 \%(10 \%)$ of the Coriolis parameter for cyclones (anticyclones). These thresholds are empirically chosen, based on typical Arctic region values.

The calculated space-averaged values (for each day) may have different levels of reliability, owing to the internal inhomogeneity of the motion field. We characterised this using the coefficient of variation $\left(c_{v}\right)$. It was found that situations with a $c_{\mathrm{v}}>1.5$ were relatively rare, and were observed only in approximately $10 \%-20 \%$ of cases for each type of circulation ( $30 \%$ for the cyclonic type). Therefore, such "unstable" forms were used together with the prevailing "stable" forms for a certain CWT. A specific hybrid weather type (see [21]) was not introduced into consideration.

The occurrence of CWT frequencies was compared with different indexes, describing the important modes of variability of meteorological conditions. They are the North Atlantic Oscillation (NAO), the summer NAO, the Scandinavian teleconnection pattern (SCAND), the East Atlantic (EA) and the East Atlan- 
tic/Western Russia (EAWR) for the Arctic-European-East Atlantic sector.

The NAO and EA are meridional waves. The pattern of anomalies consisting of the positive phase of the EA resembles the pattern of the positive phase $\mathrm{NAO}^{+}$. However, the dipole NAO is located to the north. Because of this, its influence on the Arctic region is much more pronounced. The EAWR and SCAND are zonal structures. If the EAWR pattern is located in the middle latitudes of the sector, then the SCAND pattern is located to the north, therefore its influence on the BS/KS region is much more effective. The monthly NAO and SCAND indexes were obtained from the National Oceanic and Atmospheric Administration (NOAA)/Climate Prediction Center (www.cpc.noaa.gov) and other sources.

Apart from mentioned patterns we use the specific index characterizing the influence of the Siberian High.

Based on the analysis of the frequency of the CWTs, we analysed the associated anomalies of meteorological fields. The priority in determining the origin of anomalies relates to advection processes. The role of the transformation of air masses is considered indirectly.

\section{Circulation over the Barents and Kara Seas and the Relationship with the Modes of Variability}

The separation of circulation features into several types made it possible to compose a histogram (Figure 2). CWTs corresponding to the directions from south to north are most often found in the cold season. In summer, on the contrary, air movements from the north are more typical. This seasonal change can be interpreted as a manifestation of monsoon properties. Summing up (see Figure 2) the frequencies for winter corresponding to the southern flows, we obtain $45 \%$ for BS and $55 \%$ for KS. The frequencies of the northern flows for summer are $48 \%$ for BS and $68 \%$ for KS. This quantitatively coincides with those presented in an earlier work based on station observations [8].

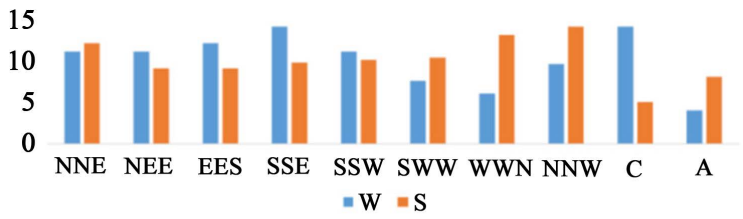

(a)

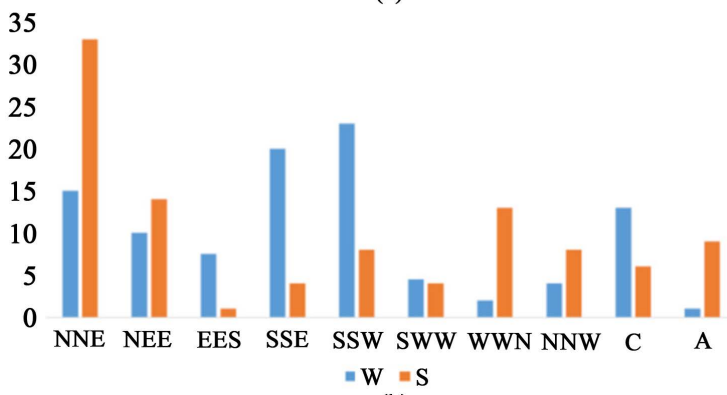

(b)

Figure 2. Frequency (\%) of circulation weather types for the Barents Sea (a) and the Kara Sea (b) regions. $W$ shows the histogram values for winter and $S$ for summer. 
The two-dimensional distribution function of the frequencies of the CWTs and wind speed is shown in Figure 3. The wind speed in the cold season is greater than in summer, increasing from approximately 2 to $5-8 \mathrm{~m} / \mathrm{s}$, and in more rare cases, up to $10 \mathrm{~m} / \mathrm{s}$ or more.

During the summer, the north winds are observed together more often with almost any CWTs. The same situation is observed during the spring and autumn. In winter, the "southern" CWTs are more pronounced (especially for the $\mathrm{KS}$ ), and anticyclonic forms of circulation and western types are less common. As will be shown below, the absence of a sharp predominance of certain wind directions reflects the result of formal averaging when events associated with different modes of variability are mixed.

As already noted, the BS and KS are characterised by cyclonic activity in all seasons. Such a specific character of climate conditions can be illustrated by using a picture of a synoptic activity distribution, which is quantified as the variance of the 2.5 - 6 day band, passed filtered daily sea level pressure data (Figure 4). This variable is generally denominated storm track activity. During the cold period, there is one region of high baroclinicity, situated over the North Atlantic and the western part of the BS. This area sees the formation of cyclones whose intensification is favoured by the diabatic heating and moisture supply provided by the ocean. These results are similar to those of other researchers [18] [26] [27] [28]. The intensity of the cyclonic activity gradually decreases from west to east, and cyclones are usually destroyed in the Yamal-Taimyr region, which in the synoptic jargon is figuratively called the "cemetery of cyclones".
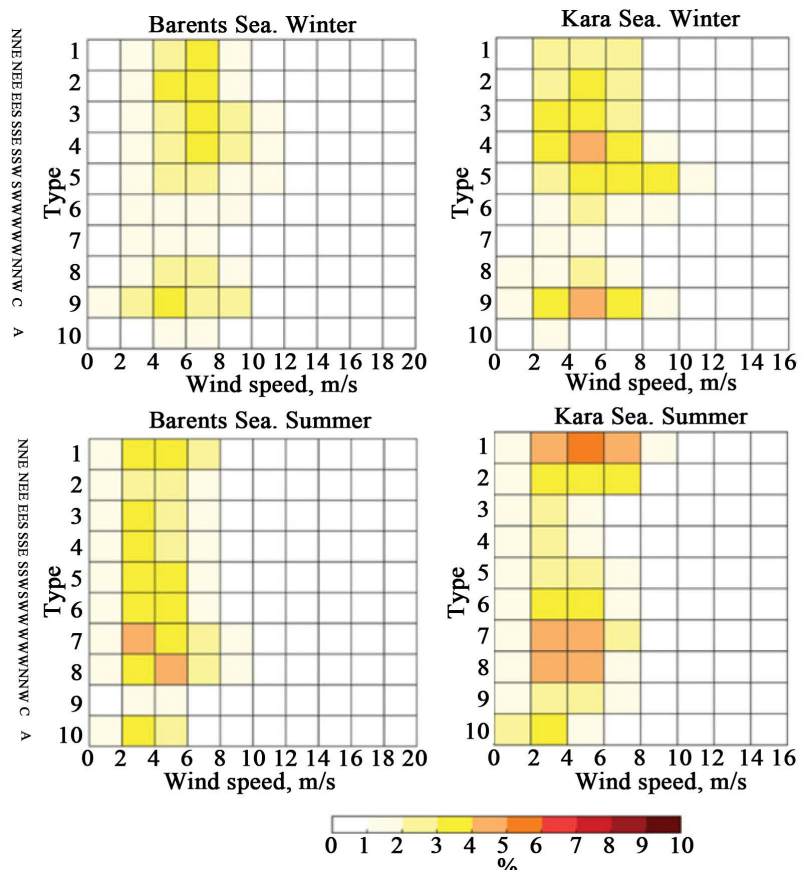

Figure 3. The two-dimensional distribution function of the frequencies of the CWTs and wind speed for the Barents and Kara Seas, winter and summer seasons. The coordinate axis are the circulation weather types (ordinate axis) and velocities (abscissa axis). 


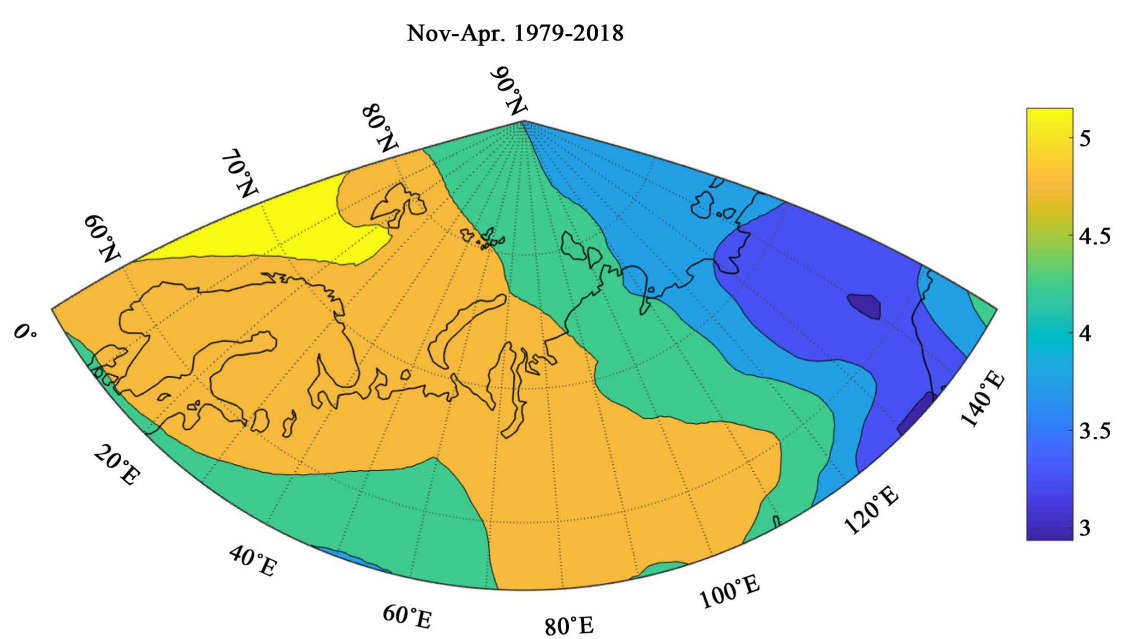

(a)

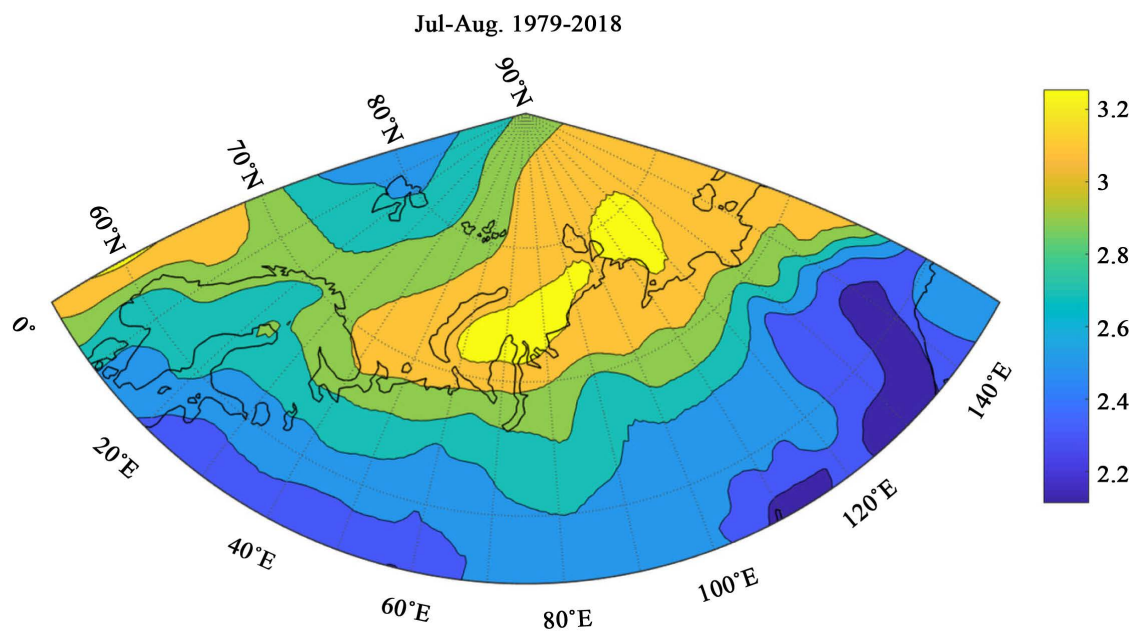

(b)

Figure 4. Spatial distribution of the variance of the 2.5 - 6 day band, passed filtered daily sea level pressure data for winter and summer seasons.

During summer time, there are two regions of high synoptic activity. One is located over the Norwegian Sea, and another is over the KS and the Laptev Sea (Figure 4(b)). The latter characterises the strong meridional gradients of surface temperatures, owing to the contrasts between the warm continent and cool ocean. Here, the fading synoptic systems coming from the west receive a new impetus for re-development.

The impact of the North Atlantic on the meteorological regime of the BS and KS can be assessed by analysing the relationship between the CWTs and the main modes of variability. For winter, the main modes of variability are the NAO and SCAND.

The NAO index is a measure of the degree of zonality of the circulation associated with the North Atlantic centres of action (the Azores High and the Iceland Depression). The SCAND index characterises the intensity of meridional circulation. 
It is known that the variability of the NAO is characterised by a type of "cluster" behaviour. In 1980-1990, positive phases $\left(\mathrm{NAO}^{+}\right)$dominated. Then came a long period of weak signals with predominance of the $\mathrm{NAO}^{-}$, which has been replaced in the past few years by positive phases.

These features are reflected in Figure 5, where we present the NAO index dynamics for the BS and KS, plotted in a coordinate system of years (along the ordinate axis) and CWTs (along the abscissa axis). It can be seen that over the BS, the southern CWTs correspond to the $\mathrm{NAO}^{+}$in 1983, 1986-1995, 2004, 2012, 2015-2018 years. Over the KS, the southern CWTs correspond to the $\mathrm{NAO}^{+}$in 1983, 1987-1995, 2000, and 2012-2018 years.

In the BS, the northern CWTs correspond to the $\mathrm{NAO}^{-}(1979,1985,1987$, 1988, 2001, 2010, 2011, 2013 on Figure 5(a)). The calendar for the KM is different; there are negative stages in 1979, 1980, 1983, 1996, 1997, 2006, and 2010, and twice (1986 and 1996) there is a cyclonic CWT, as shown in Figure 5(b).

The other primary mode of variability for the BS and KS is the SCAND. Its positive phase is depicted by the anticyclone over the north of the Scandinavia and the depression over Siberia. It should be noted that the NAO and the SCAND are not comparable in their contribution to the variability of the pressure field; therefore, the SCAND is important when the impact of NAO is small. With this in mind, we will consider the situation from the mid-1990s to 2015, during a period of weak NAO signals. At this time, the positive phases of the SCAND prevailed, and, consequently, western flows should correspond to this anomaly for the BS. Such CWTs are observed at this time (Figure 6(a)). A situation similar to that considered for the BS was observed over the KS, but only in 1994-1996 (Figure 6(b)). In other years, there is no unambiguous relationship between SCAND anomalies and the CWTs. Apparently, this is a consequence of the fact that the SCAND characterises an anomaly of a regional scale, the effect of which weakens outside the region of its maximum influence, whereas the $\mathrm{NAO}$ is, in fact, a manifestation of the planetary annular mode.

During winter, atmospheric circulations over the BS and especially over the KS are partly influenced by airflows of the western periphery of the Siberian High. This movement creates southern winds, contributing to the formation of

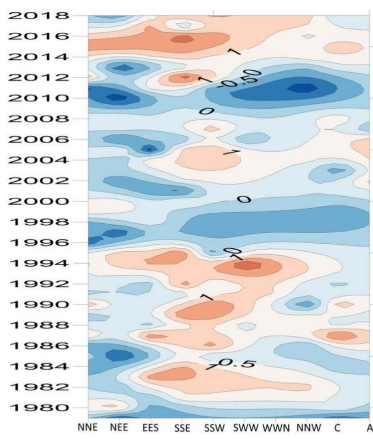

(a)

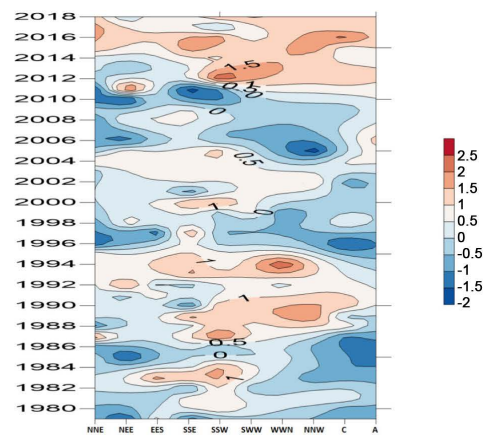

(b)

Figure 5. The NAO index dynamics for the Barents (a) and Kara (b) Seas, plotted in a coordinate system of years (along the ordinate axis) and CWTs (along the abscissa axis). 


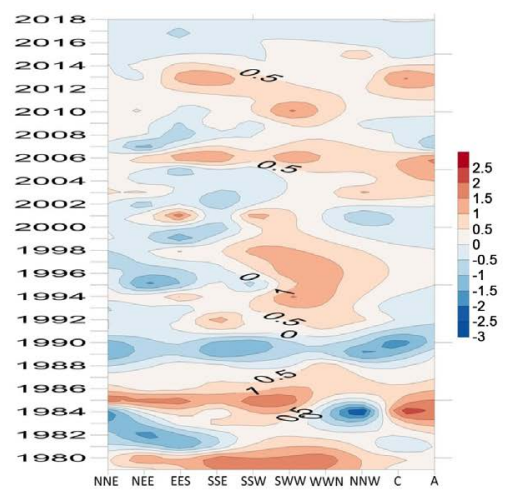

(a)

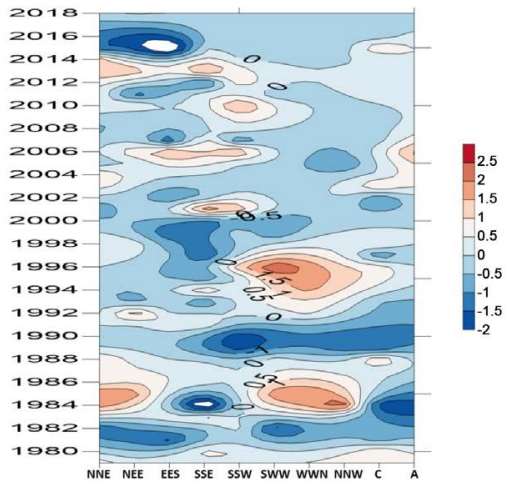

(b)

Figure 6. The SCAND index dynamics for the Barents (a) and Kara (b) Seas, plotted in a coordinate system of years (along the ordinate axis) and CWTs (along the abscissa axis).

monsoon features of the region. We compared the CWTs with the intensity index of the Siberian anticyclone, using the "Siberian High index" (SH index) for quantitative analysis. We use a slightly-modified version of the observation-based SH index [29]. They used the normalised mean sea level pressure from 11 stations located in a key region between $40^{\circ} \mathrm{N}-65^{\circ} \mathrm{N}$ and $80^{\circ} \mathrm{E}-120^{\circ} \mathrm{E}$. Here, we employ data from the same 10 stations. One station located at a height of approximately $1.3 \mathrm{~km}$ was excluded, because this data are not entirely suitable to characterise a low-level anticyclone. First, we investigated the connection between the SH index and the NAO index, and found out a negative weak correlation $(-0.35)$. The negative correlation had been observed before [30]. The previous researchers reported on negative correlations between the $\mathrm{SH}$ and the Arctic Oscillation (AO), but the NAO can be seen as part of the AO. However, in [31] pointed out that the $\mathrm{SH}$ index and $\mathrm{AO}$ time series varied such that they were not always out of phase, and over some periods, were even positively correlated. The small values of the correlation coefficients and the complex character of the relationship can be interpreted as a sign of independence (in a statistical sense) of the NAO and the SH index. Matching the CWTs with the dynamics of the $\mathrm{SH}$ index did not show reasonable results. The main practical reason for the absence of correlations is that the variations of the SH index are much slower than the variations of the CWTs.

Therefore, our analysis shows that southern flows (as a monsoon sign during the cold season) exist only with the $\mathrm{NAO}^{+}$. Such events are observed almost synchronously over the BS and the KS, because at a positive NAO stage, the zonal character of circulation intensifies. For $\mathrm{NAO}^{-}$and SCAND, there is no 'proper' winter monsoon circulation. In addition, the links between the meteorological conditions of the BS and the KS are weakened when meridional circulation prevails.

In summer, the NAO does not correlate with the anomalies of meteorological fields. This is because the inter-latitudinal temperature gradient decreases, and the mechanisms of planetary control weaken. Nevertheless, it is believed that this situation can be corrected by introducing a "summer NAO" (sNAO) [32]. Its use 
allows us to identify some features of atmospheric teleconnections in the warm season. The $\mathrm{sNAO}^{+}$is characterised by a high pressure area over the Norwegian Sea, Scandinavia, and the $\mathrm{BS}$ and $\mathrm{KS}$. In contrast, $\mathrm{sNAO}^{-}$is characterised in this region by a zone of low pressure. On this basis, $\mathrm{sNAO}^{+}$should correspond to the northern winds over the western sector of the Arctic, reflecting the correct monsoon circulation.

A comparison of the state of the sNAO with the CWTs is performed similarly to how it was performed for the other indices in winter conditions. First, we note that the drawings for the BS and KS are very similar (Figure 7). This means that circulation systems are interconnected over these regions. However, the correspondence between the sNAO and the CWTs can be different. For example, during the $\mathrm{sNAO}^{-}$instances in 1990,1991 , and 2008, northern winds prevailed. However, in the same phases of 1988 and 1992, northerly winds alternated with southeast winds. With $\mathrm{sNAO}^{+}$, the combinations of the CWTs can also be different. For example, easterly CWTs prevailed in 1982, 1983, 1984, and 2013-2016; but in 1996-1998 and 2003-2004, westerly CWTs prevailed. Therefore, we can state that a clear connection is not fixed. This confirms the concept of a general weakening of planetary relations and the increasing role of regional-scale effects. These aspects will be discussed in the next chapter.

\section{Anomalies in Wind Speed, Temperature, and Precipitation}

The abnormally-high wind speeds for the Arctic region have been previously studied [33]. Here, we compare the appearance of extrema wind speeds with the CWTs. It should be pointed out that coarse resolution reanalysis data do not fully reproduce the largest anomalies of wind speed. However, the proposed approach can be considered satisfactory if the anomalies do not exceed too large of a quantile value. Therefore, we select, in the series belonging to each region, the anomalies of the velocities for $\mathrm{p}>0.95$.

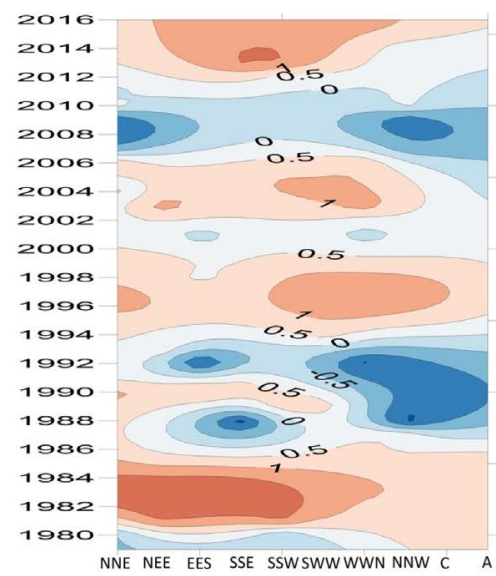

(a)

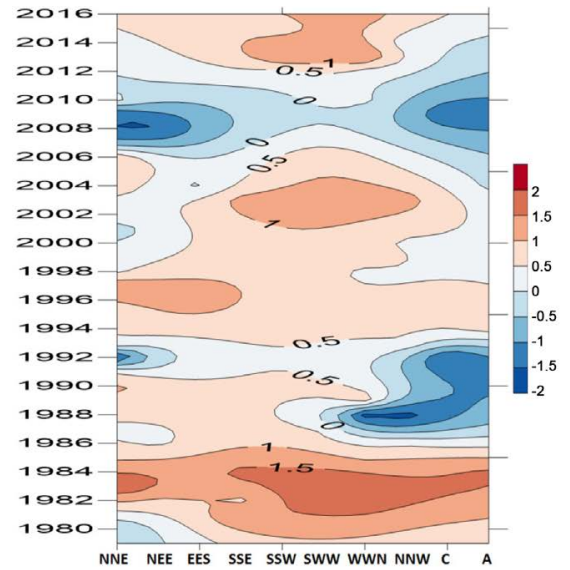

(b)

Figure 7. The sNAO index dynamics for the Barents (a) and Kara (b) Seas, plotted in a coordinate system of years (along the ordinate axis) and CWTs (along the abscissa axis). 
In winter, the maximum velocities fall on the southern flows, and in summer, on the northern flows (Figure 8). Thus, the monsoon character is manifested in statistics of extreme values, even without the selection of data on the modes of variability. Over the BS in winter, the main role belongs to the CWT = SSE, and over the KS, the CWT $=$ SSW. For summer over the BS, CWT $=\mathrm{NNW}$, and over the KS, the CWT = NNE. In transition seasons, the distribution of extrema is bimodal (Figure 8). Therefore, in the cold period, the extreme winds are southerly winds that develop in the eastern parts of cyclones. In the warm season, the extreme speeds correspond to a northerly wind in the western periphery of cyclones.

The second case is more interesting, as it illustrates the above-mentioned role of regional processes during the summer. An example of the synoptic situations leading to the long existence of the northern streams is shown in Figure 9. A cyclone was located on June 10.06.2019 over the northern part of the Scandinavian Peninsula and the Cola Peninsula (Figure 9(a)), and the next day had approached the KS. In combination with other vortices, it formed a vast depression (Figure 9(b)). At this time, a stream of northern air had already formed (by the way, the temperature dropped by more than $15^{\circ} \mathrm{C}$, as seen by comparing the data of the stations in Figure 9(a) and Figure 9(b)). The next day, the depression turned into a vortex over the KS and existed for a long time (see the situation on 15.06.2019 in Figure 9(c)). This vortex dissipated on 20.06.2019, but after a few days, the same synoptic situation recovered again. In general, during June and half of July 2019, the BS and the KS were dominated by northern winds, generated on the western periphery of cyclones stabilised over the KS.

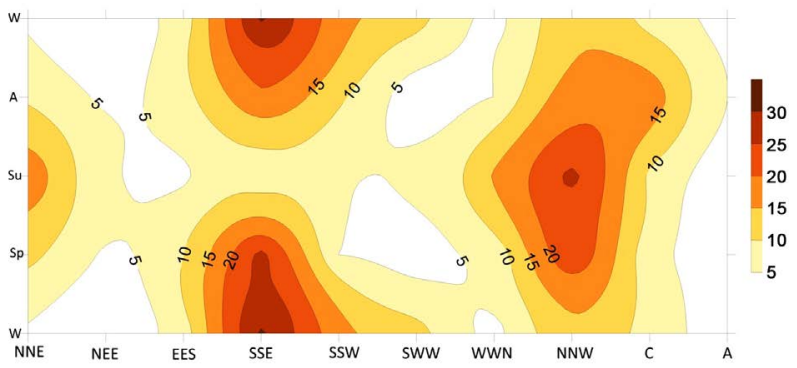

(a)

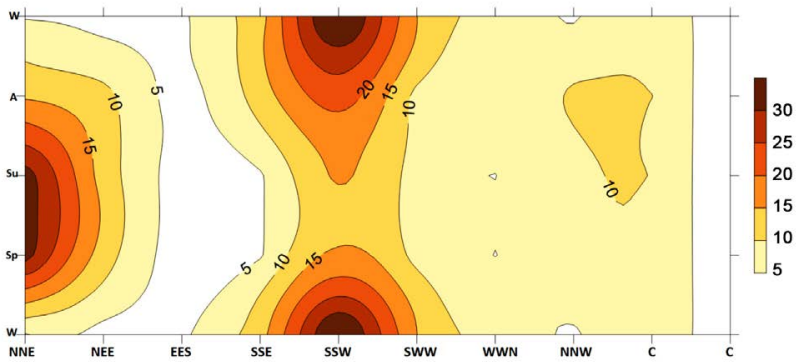

(b)

Figure 8. Frequencies of the anomalies values (for $\mathrm{p}>0.95$ ) of wind velocities, plotted in a coordinate system consisting of the seasons (along the ordinate axis) and the CWTs (along the abscissa axis). For the Barents Sea (a) and Kara Sea (b). 


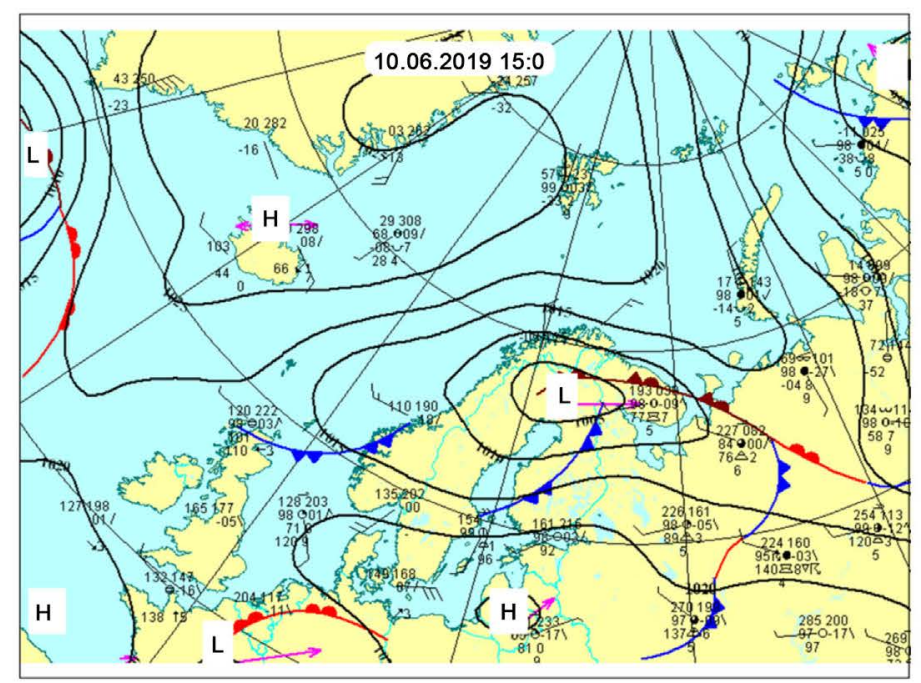

(a)

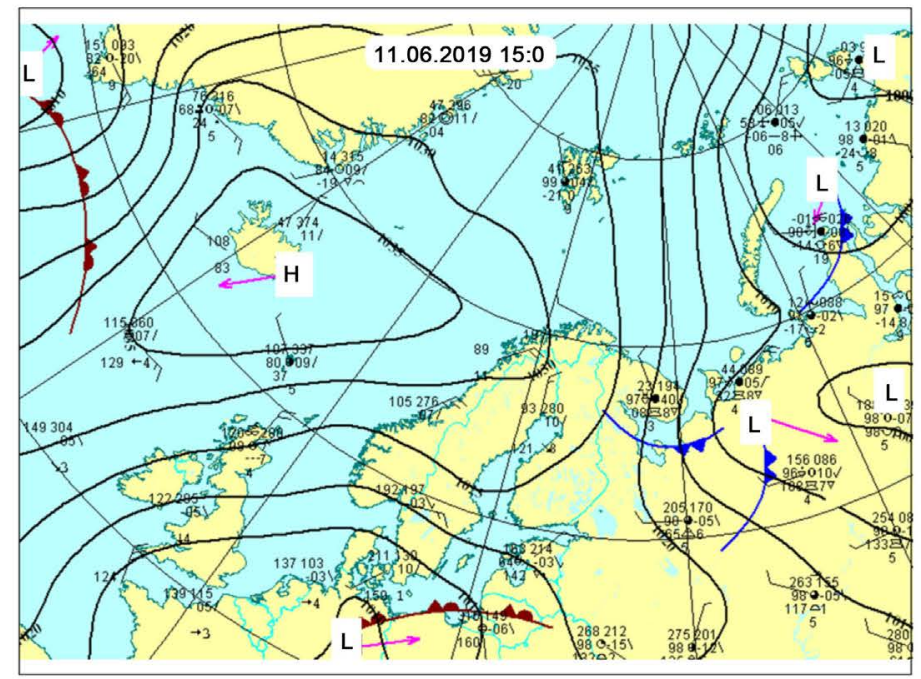

(b)

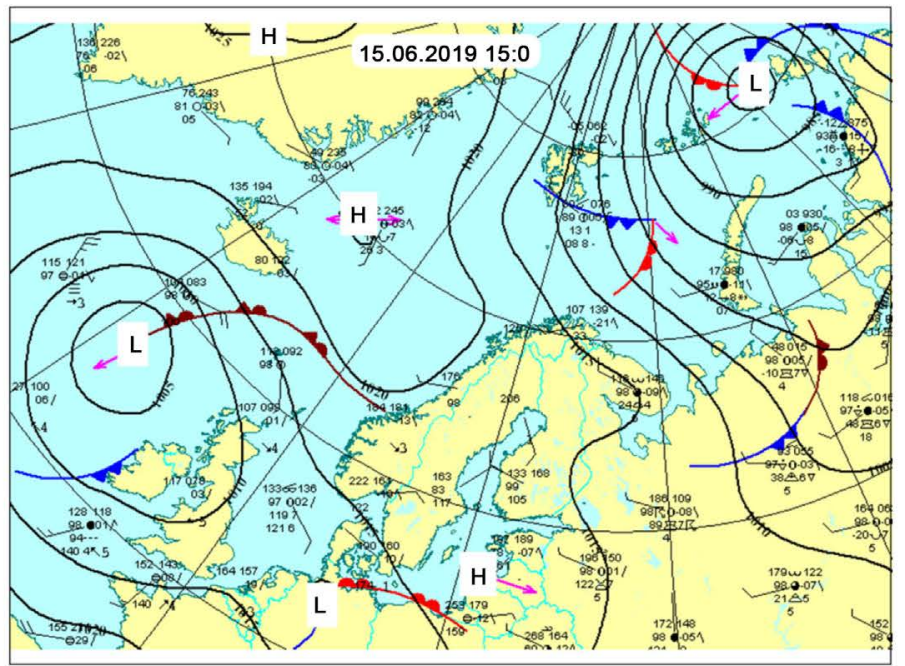

(c)

Figure 9. Weather maps valid 15 UTC 10, 11, 15 June 2019. 
Now, we turn to the temperature near the marine surface. We perform a statistical analysis using the CWTs as a basis. The air temperature in the BS in the warm season is approximately $6^{\circ} \mathrm{C}-9^{\circ} \mathrm{C}$. These values are approximately equally distributed among different CWTs (figure not shown). This uniformity means that the transformation of an air mass of any origin occurs very quickly over the cold sea surface. In autumn, the situation is the same, but the temperature range increases from $3^{\circ} \mathrm{C}$ to $9^{\circ} \mathrm{C}$.

In winter, the temperature differences are much greater. They are from approximately $-20^{\circ} \mathrm{C}$ to $+6^{\circ} \mathrm{C}$. The main reason is that a significant part of the marine surface is covered with ice. Positive temperatures and temperatures near zero are associated with southern CWTs when a powerful atmospheric transport does not allow enough time to transform warm air when it moves over a cold continent.

As far as extreme values are concerned, we distinguish the anomalous values of air temperature (for $\mathrm{p}>0.95$ ) in the series belonging to different seasons. Frequencies of anomalies $\mathrm{T}(\mathrm{p}>0.95)$ are plotted in a coordinate system consisting of the seasons (along the ordinate axis) and the CWTs (along the abscissa axis) (Figure 10). For winter and autumn, the anomalies are associated with southwest CWTs. The range of the CWTs in the summer is much wider than that in other seasons. This means that in the summer, practically any flows from the land provide heat advection, leading to a large positive temperature anomaly over the BS and KS.

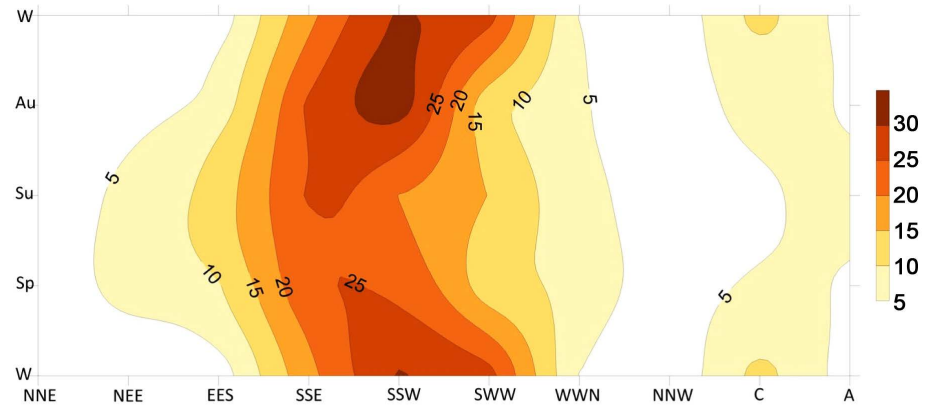

(a)

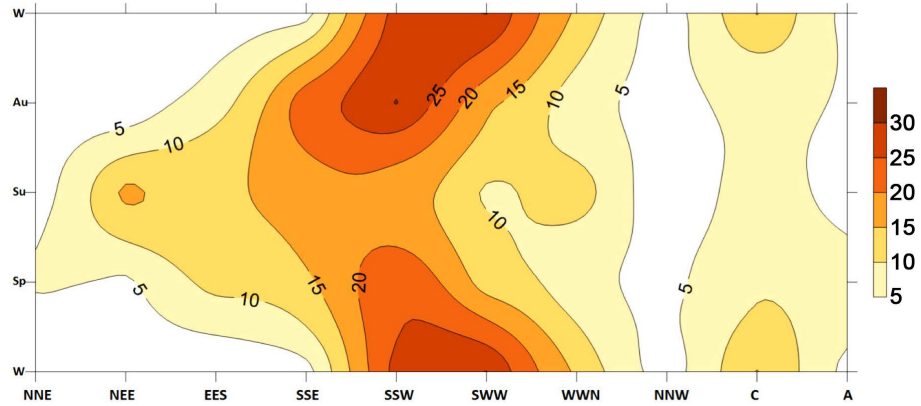

(b)

Figure 10. Frequencies of anomalies values (for $\mathrm{p}>0.95$ ) of the temperature, plotted in a coordinate system consisting of the seasons (along the ordinate axis) and the CWTs (along the abscissa axis). For the Barents Sea (a) and Kara Sea (b). 
The largest frequency of cold anomalies $(\mathrm{p}<0.05)$ in winter over the BS is associated with north and northeast CWTs (Figure 11(a)), whereas above the KS, the range of the CWTs is much wider, and mainly includes easterly winds (Figure 11(b)). In the summer, the cold anomalies for the BS are formed by northern (and especially northwestern) CWTs that deliver arctic air masses from Greenland (Figure 11(a)). Within the KS, cold anomalies are associated with northern and northeastern CWTs bringing cold air from polar regions covered with perennial ice, whereas the source of cold air from the Greenland is less pronounced.

Large anomalies of precipitation (at $\mathrm{p}>0.95$ ) during all seasons are maximally frequent, as one would expect with a cyclonic type of circulation (Figure 12).

\section{Discussion}

The analysis showed that over the BS and KS, monsoon features take place (especially they are pronounced for selected years). However, traditional monsoon region interpretation (when the winter anticyclonic regime is opposed to the summer cyclonic regime) is not applicable here, as the number of cyclones is large in both summer and winter, and the seasonal sum of precipitation (another important monsoon indicator) also does not contain the necessary regularities. In winter, the monsoon circulation features (southern air streams from land to sea) are mainly manifested together with the positive phase of the NAO. During the $\mathrm{NAO}^{-}$, various combinations of regional circulation systems are possible.

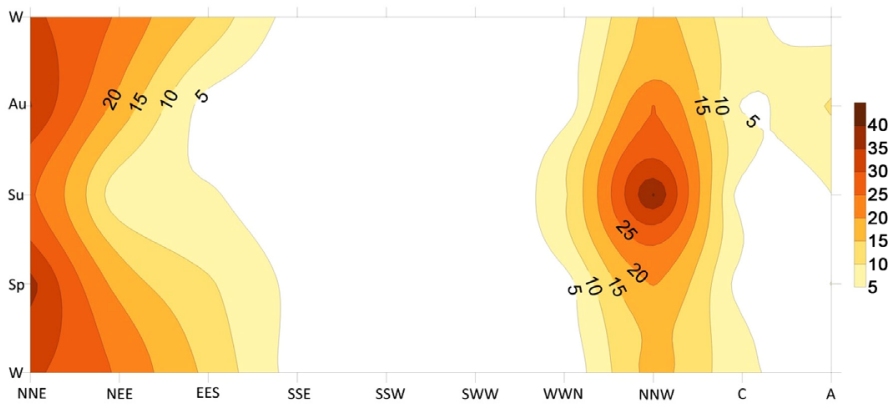

(a)

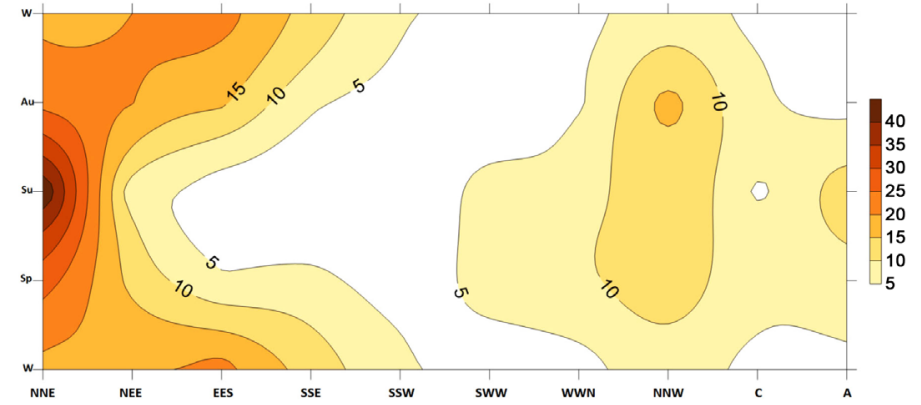

(b)

Figure 11. Frequencies of anomalies values (for $\mathrm{p}<0.05$ ) of the temperature, plotted in a coordinate system consisting of the seasons (along the ordinate axis) and the CWTs (along the abscissa axis). For the Barents Sea (a) and Kara Sea (b). 


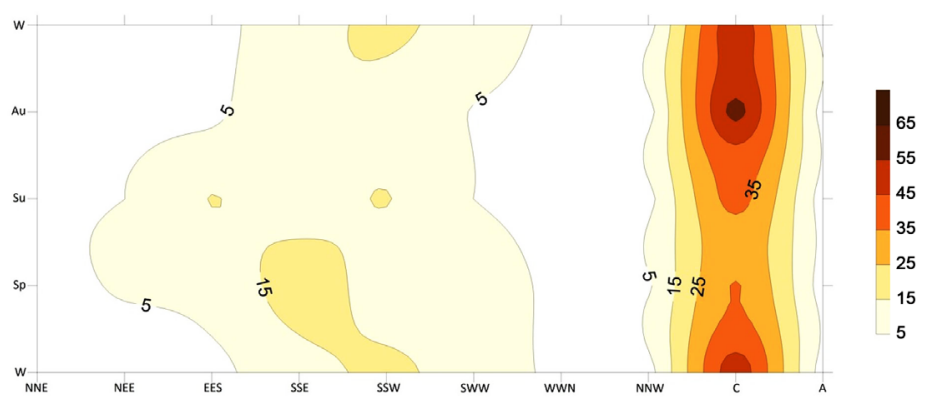

(a)

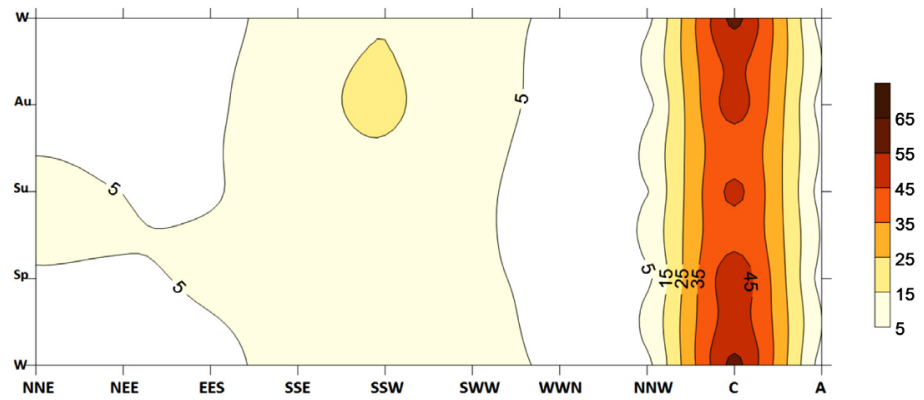

(b)

Figure 12. Frequencies of anomalies values (for $\mathrm{p}>0.95$ ) of the precipitations, plotted in a coordinate system consisting of the seasons (along the ordinate axis) and the CWTs (along the abscissa axis). For the Barents Sea (a) and Kara Sea (b).

The latter conclusion should mean that despite the fact that cyclones are present over arctic seas in all seasons, their behaviour has somewhat different results for $\mathrm{NAO}^{+}$and $\mathrm{NAO}^{-}$. Different authors have discussed this subject with conflicting results. Thus, differences in the frequency of cyclones with $\mathrm{NAO}^{+}$ and $\mathrm{NAO}^{-}$were not detected [18]. However, it was shown that the differences in the dynamics of cyclones with $\mathrm{NAO}^{+}$and $\mathrm{NAO}^{-}$are significant in late autumn and early winter, when $\mathrm{NAO}^{-}$vortices do not go far east along the Siberian coast [34]. Keeping in mind that cyclones slow down, stabilise, and finally dissipate in the Yamal-Taimyr region, this means that they form and support a zone of northern flows over the BS and the KS. These are absolutely non-monsoon flows for the winter. With the $\mathrm{NAO}^{+}$, cyclones penetrating far to the east create both southern and northern air flows over BS and KS (in the eastern and western parts of the vortex, respectively). However, a symmetric effect is not observed. As shown above, the southern flows are more significant in terms of the formation of anomalies. As indirect confirmation of the predominance of southern flows is clearly monitored from the increase with the $\mathrm{NAO}^{+}$in spring flood volumes in the rivers of the region along the coast [35]).

In the summer, as already noted, the planetary mechanisms for managing regional circulations weaken. In this case, the monsoon features can be explained if we consider the role of the secondary baroclinic region located over the KS and the Laptev Sea (see Figure 4(b)). On the western periphery of the cyclones regenerating there, quasi-stable northern flows are formed (Figure 9(c)). 


\section{Conclusions}

In the BS and KS, the seasonal wind regime has monsoon features, despite an active cyclogenesis throughout the year. Monsoon currents from land to sea in the winter season occur only with the $\mathrm{NAO}^{+}$. The extreme wind velocities are southerly winds that develop in the eastern parts of cyclones. With the prevalence of other modes of variability, the direction of the winds can be different, and this causes the monsoon regularity to be stochastic.

In summer, northern streams are created on the western periphery of cyclones, regenerating and stabilizing over the KS. This mechanism develops under the influence of the geographical features of the Barents and Kara Seas and coasts, as well as regional heat balance peculiarities and circulation processes.

\section{Funding}

The work was supported by the grant of the Russian Foundation for Basic Research (RFBR) [project number 18-05-60147] and this work was carried out as part of governmental assignment AAAA-A16-116032810086-4.

\section{Conflicts of Interest}

The authors declare no conflicts of interest regarding the publication of this paper.

\section{References}

[1] Serreze, M.C. and Barry, R.G. (2011) Processes and Impacts of Arctic Amplification: A Research Synthesis. Global and Planetary Change, 77, 85-96. https://doi.org/10.1016/j.gloplacha.2011.03.004

[2] Cohen, J., Screen, J.A., Furtado, J.C., Barlow, M., Whittleston, D., Coumou, D., Francis, J., Dethloff, K., Entekhabi, D., Overland, J. and Jones, J. (2014) Recent Arctic Amplification and Extreme Mid-Latitude Weather. Nature Geoscience, 7, 627-637. https://www.nature.com/articles/ngeo2234 https://doi.org/10.1038/ngeo2234

[3] Marshall, G.J., Vignols, R.M. and Rees, W.G. (2016) Climate Change in the Kola Peninsula, Arctic Russia, during the Last 50 Years from Meteorological Observations. Journal of Climate, 29, 6823-6839. https://doi.org/10.1175/JCLI-D-16-0179.1

[4] Ye, K., Wu, R. and Liu, Y. (2015) Interdecadal Changes of Eurasian Snow, Surface Temperature and Atmospheric Circulation in the Late 1980s. Journal of Geophysical Research: Atmospheres, 120, 2738-2753. https://doi.org/10.1002/2015JD023148

[5] World Atlas in Physical Geography. 1964. Moscow. http://www.atlassen.info/atlassen/russisch/fzgat01/picsxl/fzgat1964k040041.jpg

[6] Shrader, T.A. (2005) Across the Borders: The Pomor Trade. In: Jackson, T.N. and Nielsen, J.P., Eds., Russia-Norway. Physical and Symbolic Borders, Languages of Slavonic Culture, Moscow, 105-115.

[7] Karpovich, L.I. (2014) Russian Arctic in the 16th Century. Proceedings of International Confernce "InterCarto/InterGIS", Vol. 20, 470-473. https://doi.org/10.24057/2414-9179-2014-1-20-470-473

[8] Khromov, S.P. (1957) Die geographische Verbreitung der Monsune. Petermanns 
Geographische Mitteilungen, 101, 234-237.

[9] Ramage, C.S. (1971) Monsoon Meteorology. Academic Press, New York and London, $300 \mathrm{p}$.

[10] Krishnamurti, T.N. (1979) Tropical Meteorology. Compendium of Meteorology II, WMO No. 364. World Meteorological Organization, Geneva, 428 p.

[11] Adams, D.K. and Comrie, A.C. (1997) The North American Monsoon. Bulletin of the American Meteorological Society, 78, 2197-2213. https://doi.org/10.1175/1520-0477(1997)078<2197:TNAM>2.0.CO;2

[12] Webster, P.J., Magana, V.O., Palmer, T.N., Shukla, J., Tomas, R.A., Yanai, M. and Yasunari, T. (1998) Monsoons: Processes, Predictability, and the Prospects for Prediction. Journal of Geophysical Research: Oceans, 103, 14451-14510. https://doi.org/10.1029/97JC02719

[13] Wang, B. and Ding, Q. (2008) Global Monsoon: Dominant Mode of Annual Variation in the Tropics. Dynamics of Atmospheres and Oceans, 44, 165-183. https://doi.org/10.1016/j.dynatmoce.2007.05.002

[14] Silva, V.B.S. and Kousky, V.E. (2012) The South American Monsoon System: Climatology and Variability. In: Wang, S.-Y. and Gillies, R.R., Eds., Modern Climatology Full Text, InTech, London, 15. https://digitalcommons.usu.edu/modern_climatology/15

[15] Semenov, E.K. and Korniushin, O.G. (1988) Atlas of Circulation Characteristics in the Troposphere and Lower Stratosphere of the Tropical Zone. Gidrometizdat, Moscow, 105 p. (In Russian)

[16] Trenberth, K.E., Stepaniak, D.P. and Caron, J.M. (2000) The Global Monsoon as Seen through the Divergent Atmospheric Circulation. Journal of Climate, 13, 3969-3993. https://doi.org/10.1175/1520-0442(2000)013<3969:TGMAST>2.0.CO;2

[17] Thompson, D.W.J. and Wallace, J.M. (1998) The Arctic Oscillation Signature in Wintertime Geopotential Height and Temperature Fields. Geophysical Research Letters, 25, 1297-1300. https://doi.org/10.1029/98GL00950

[18] Bardin, M.Yu., Platova, T.V. and Samokhina, O.F. (2015) Specific Features of Variability of Cyclone Activity in Northern Extratropics Associated with Leading Atmospheric Circulation Modes in Atlantic-European Sector. Fundamental and Applied Climatology, 2, 14-40. (In Russian)

http://downloads.igce.ru/journals/FAC/FAC_2015/FAC_2015_2/Bardin_M_Yu_etc _FAC_2015_N2_04122015.pdf

[19] Popova, V.V. (2018) Present-Day Changes in Climate in the North of Eurasia as a Manifestation of Variation of the Large-Scale Atmospheric Circulation. Fundamental and Applied Climatology, 1, 84-111. (In Russian) https://doi.org/10.21513/2410-8758-2018-1-84-111

[20] Dee, D.P., Uppala, S., Simmons, A., Berrisford, P., Poli, P., Kobayashi, S., Andrae, U., Balmaseda, M.A., Balsamo, G., Bauer, P., Bechtold, P., Beljaars, A.C.M., van de Berg, L., Bidlot, J.-R., Bormann, N., Delsol, C., Dragani, R., Fuentes, M., Geer, A., Haimberger, L., Healy, S., Hersbach, H., Holm, E.V., Isaksen, L., Kallberg, P.W., Kohler, M., Matricardi, M., McNally, A., Monge-Sanz, B.M., Morcrette, J.-J., Park, B.-K., Peubey, C., De Rosnay, P., Tavolato, C., Thepaut, J.-J. and Vitart, F. (2011) The ERA-Interim Reanalysis: Configuration and Performance of the Data Assimilation System. Quarterly Journal of the Royal Meteorological Society, 553, 553-597. https://doi.org/10.1002/qj.828

[21] Jones, P.D., Hulme, M. and Briffa, K.R. (1993) A Comparison of Lamb Circulation Types with an Objective Classification Scheme. International Journal of Climatolo- 
gy, 13, 655-663. https://doi.org/10.1002/joc.3370130606

[22] Jones, P.D., Harpham, C. and Briffa, K.R. (2012) Lamb Weather Types Derived from Reanalysis Products. International Journal of Climatology, 33, 1129-1139. https://doi.org/10.1002/joc.3498

[23] Weusthoff, T. (2011) Weather Type Classification at MeteoSwiss-Introduction of New Automatic Classifications Schemes. Arbeitsberichte der MeteoSchweiz 235, 46 p.

[24] Kislov, A.V., Surkova, G.V. and Arkhipkin, V.S. (2016) Occurrence Frequency of Storm Wind Waves in the Baltic, Black, and Caspian Seas under Changing Climate Conditions. Russian Meteorology and Hydrology, 41, 121-129. https://doi.org/10.3103/S1068373916020060

[25] Bielec-Bąkowska, Z. and Widawski, A. (2018) Strong Anticyclones and Deep Cyclones over Svalbard in the Years 1971-2015. Boreal Environment Research, 23, 283-297.

[26] Hanley, J. and Caballero, R. (2012) Objective Identification and Tracking of Multicentre Cyclones in the ERA-Interim Reanalysis Dataset. Quarterly Journal of the Royal Meteorological Society, 138, 612-625. https://doi.org/10.1002/qj.948

[27] Tilinina, N.D., Gulev, S.K., Rudeva, I. and Koltermann, P. (2013) Comparing Cyclone Life Cycle Characteristics and Their Interannual Variability in Different Reanalyses. Journal of Climate, 26, 6419-6438.

https://doi.org/10.1175/JCLI-D-12-00777.1

[28] Shaw, T.A., Baldwin, M., Barnes, E.A., Caballero, R., Garfinkel, C.I., Hwang, Y.-T., Li, C., O’Gorman, P.A., Rivière, G., Simpson, I.R. and Voigt, A. (2016) Storm Track Processes and the Opposing Influences of Climate Change. Nature Geoscience, 9 , 656-664. https://doi.org/10.1038/ngeo2783

[29] Panagiotopoulos, F., Shahgedanova, M., Hannachi, A. and Stephenson, D.B. (2005) Observed Trends and Teleconnections of the Siberian High: A Recently Declining Center of Action. Journal of Climate, 18, 1411-1422. https://doi.org/10.1175/JCLI3352.1

[30] Gong, D.-Y. and Ho, C.-H. (2002) The Siberian High and Climate Change over Middle to High Latitude Asia. Theoretical and Applied Climatology, 72, 1-9. https://link.springer.com/content/pdf/10.1007/s007040200008.pdf https://doi.org/10.1007/s007040200008

[31] Huang, W., Wang, B., Wright, J.S. and Chen, R. (2016) On the Non-Stationary Relationship between the Siberian High and Arctic Oscillation. PLOS ONE, 11, e0158122. https://doi.org/10.1371/journal.pone.0158122

[32] Folland, C.K., Knight, J., Linderholm, H.W., Fereday, D., Ineson, S. and Hurrell, J.W. (2009) The Summer North Atlantic Oscillation: Past, Present and Future. Journal of Climate, 22, 1082-1103. https://doi.org/10.1175/2008JCLI2459.1

[33] Kislov, A. and Matveeva, T. (2016) An Extreme Value Analysis of Wind Speed over the European and Siberian Parts of Arctic Region. Atmospheric and Climate Sciences, 6, 205-223. https://doi.org/10.4236/acs.2016.62018

[34] Kryjov, V.N. (2015) October Circulation Precursors of the Wintertime Arctic Oscillation. International Journal of Climatology, 35, 161-171. https://doi.org/10.1002/joc.3968

[35] Kryjov, V.N. and Gorelits, O.V. (2019) Wintertime Arctic Oscillation and Formation of River Spring Floods in the Barents Sea Basin. Russian Meteorology and Hydrology, 44, 187-195. https://doi.org/10.3103/S106837391903004X 